\title{
DOSSIÊ
}

\section{Criatividade: educação e escrita criativa}

\author{
LiLIAN VIEIRA DA Rocha RIBEIRO ${ }^{1}$ \\ IGNACIO AGUADED ${ }^{2}$ \\ Mari Carmen Caldeiro Pedreira ${ }^{3}$
}

Resumo: Tendo em vista as profundas modificações pelas quais as sociedades estão passando nas últimas décadas, principalmente com o desenvolvimento das tecnologias de informação e comunicação, este artigo apresenta a criatividade como elemento-chave para adaptar-se às mudanças. A criatividade desempenha um papel determinante nos processos de adaptação dos indivíduos ao meio em que vivem. $\mathrm{O}$ pensamento criativo supõe uma atitude, uma perspectiva, que leva a procurar ideias, manipular conhecimento e experiência. Assim, após apresentar o que deve ser entendido por criatividade, aponta-se a necessidade de uma educação criativa e discutem-se alguns aspectos relevantes sobre a escrita criativa, apresentando, ao final, algumas sugestões de textos e jogos criativos.

Palavras-chave: Criatividade. Escrita criativa. Educação. Jogos criativos.

\section{Creativity: education and creative writing}

Abstract: Consider the profound changes that societies are going through in recent decades, especially with the development of information and communication technologies, this article presents creativity as a key element in adapting to change. Creativity plays a decisive role in the processes of adaptation of individuals to the environment in which they live. Creative thinking assumes an attitude, a perspective, that leads to seeking ideas, manipulating knowledge and experience. Thus, after presenting what should be understood by creativity, we point out the need for a creative education, as well as discuss some relevant aspects about creative writing and, finally, make some suggestions for texts and creative games.

Keywords: Creativity. Creativity texts. Education. Creative games.

\section{Creatividad: educación y escritura creativa}

Resumen: Considerando los profundos cambios que las sociedades han experimentado en las últimas décadas, especialmente con el desarrollo de las tecnologías de información y de comunicación, este artículo presenta la creatividad como un elemento 
clave para adaptarse al cambio. La creatividad juega un papel decisivo en los procesos de adaptación de los individuos al entorno donde viven. El pensamiento creativo asume una actitud, una perspectiva, que lleva a buscar ideas, a manipular el conocimiento y la experiencia. Por lo tanto, después de presentar lo que se debe entender por creatividad, señalamos la necesidad de una educación creativa, así como discutimos algunos aspectos relevantes a la escritura creativa y, finalmente, hacemos sugerencias para textos y juegos creativos.

Palabras clave: Creatividad. Escritura creative. Educación. Juegos creatives.

\section{Introdução}

Nos últimos anos, a criatividade se situou no centro dos debates em áreas tão díspares como a filosofia pós-estruturalista, a teoria literária, a ciência do caos e da complexidade, a cosmologia, a biologia evolutiva e a genética, a neurociência, a psicologia cognitiva e a inteligência artificial, a mecânica quântica e a física teórica (LOVELESS; WILLIAMSON, 2017). A criatividade é, simultaneamente, tanto um atributo quanto um processo que se verifica e se desenvolve no nível do indivíduo (GALVÃO, 1999). Sabe-se também que inúmeras variáveis concorrem para o seu desenvolvimento (OSTROWER, 2002; NONAKA; TAKEUCHI, 1997; EYSENCK, 1999), algumas no âmbito da cultura, outras mais próximas da dimensão institucional, sobretudo relacionadas à forma de gestão; por fim, há as condições que são singulares a cada indivíduo.

\section{Metodologia}

Para o entendimento do que é criatividade, pensamento ou processo criativo, busca-se identificar e caracterizar os seus parâmetros a partir da revisão de literatura em diversas áreas. Visando elucidar o tema em relação à escrita criativa, utilizam-se dados de entrevistas realizadas por Moura (2014). Para finalizar, realizou-se um levantamento para compilar as atividades e os jogos criativos em páginas da web, nomeadamente sites e blogs, como também a partir dos livros e artigos de Rodríguez-Estrada (1995, 2006, 2008), além da experiência de trabalho voltada para o fomento da criatividade nos diferentes âmbitos.

\section{Uma saída criativa}

As duas histórias apresentadas a seguir revelam a essência daquilo que se pretende dialogar neste artigo: a criatividade. Na primeira história, conta-se que, em um arranha-céu de Nova Iorque, havia queixas dos usuários "porque os elevadores eram muito lentos". A gerência consultou vários profissionais, e as soluções apresentadas foram: construir mais elevadores (a um custo eleva- 
díssimo), dar-lhes mais rapidez, coordenar seus movimentos segundo outros critérios. Um psicólogo propôs a colocação de espelhos, e essa foi a solução que funcionou. O psicólogo captou que o problema, no fundo, não era de velocidade, e sim de tédio e enfado. Assim, os espelhos mantiveram as pessoas entretidas (RODRÍGUEZ-ESTRADA, 2006).

A segunda história, bastante divulgada na internet, é a do cego e do publicitário. Havia um cego sentado na calçada em Paris, com um boné a seus pés e um pedaço de madeira, com o seguinte escrito em giz branco: "Por favor, ajude-me, sou cego". Um publicitário, que passava em frente a ele, parou e viu umas poucas moedas no boné e, sem pedir licença, pegou o cartaz, virou-o, pegou o giz, escreveu um texto diferente, voltou a colocar o pedaço de madeira aos pés do cego e foi embora. Pela tarde, o publicitário voltou a passar pelo cego que pedia esmola, porém, agora, o seu boné estava repleto de notas e moedas. O cego reconheceu as pisadas do publicitário e lhe perguntou se havia sido ele quem reescreveu seu cartaz, sobretudo querendo saber o que havia escrito ali. $\mathrm{O}$ publicitário então respondeu: "Nada que não esteja de acordo com o seu anúncio, mas com outras palavras. Está escrito: "Hoje é primavera em Paris e eu não posso vê-la” (ROSA, 2014).

Ambas revelam soluções aparentemente simples para problemas diários e apontam para a necessidade de "um novo olhar" diante da vida e das situações. Cabe salientar que, por muitos anos, o fenômeno da criatividade foi tido como um ato místico, incompreensível e inexplicável, capaz de igualar o homem ao divino por meio da criação (DOLLINGER, 2007), e foi marcado por correntes filosóficas, sociais ou científicas que desde sempre procuraram explicá-lo.

Em 1950, Guilford, alertou para a necessidade de um maior investimento nos estudos sobre a criatividade, em seu discurso de posse na Associação Americana de Psicologia. Essa intervenção provocou um crescimento exponencial dos estudos nessa matéria, de tal forma que alguns investigadores apontam um antes e um depois do discurso de Guilford (MORAIS, 2001; CARNAZ, 2013). Desses avanços, foi possível sistematizar um conjunto de teorias e correntes que, ao longo dos tempos, procuraram explicar o fenômeno da criatividade.

Entretanto, os progressos registrados não foram suficientes para eliminar do senso comum diversos preconceitos, relacionados com esse tema: associação a doenças mentais ou à sanidade mental; identificação com a excentricidade ou hiperatividade; relação com a inspiração súbita, sem trabalho e sem explicação; atributo, privilégio de poucos; confusão com termos como imaginação, novidade, inovação, originalidade. O que também foi referido por Carnaz (2013, p. 6), ao afirmar que: "criatividade é um conceito complexo. E a sua dificuldade reside não só em definir o seu construto como, também, em separar as concepções errôneas que, ao longo dos séculos, a ele foram associadas". 
Tendo em conta esses aspectos, buscar-se-á entender melhor esse fenômeno, abordando os motivos pelos quais se considera a relevância de que se produza uma educação criativa em casa e nas escolas, tendo em conta as investigações realizadas por diversos pesquisadores, como Loveless e Williamson (2017), Costa (2016), Robinson (2010, 2015), Stevenson (2015), Menchén-Bellón (2012, 2015), Carnaz (2013), Florida (2010), Seabra, (2008), Rodríguez-Estrada (2006, 2008), Chaffe (2000), Alencar (1992), Dewey (1979), entre outros, que destacam a necessidade de uma educação que desenvolva a potencialidade criativa dos educandos. Por fim, com uma visão pragmática, procurou-se trazer algumas sugestões de textos e atividades criativas para serem usadas por pais e educadores, considerando a urgência desse tema nas famílias e nas escolas.

Apontam-se a seguir algumas justificativas para fomentar a criatividade: Einstein dizia que "não podemos pretender que as coisas mudem se continuamos fazendo o mesmo" (MENCHÉN-BELLÓN, 2015); portanto, a educação criativa exige mudanças de hábitos e ruptura com o comodismo e a estagnação. Enquanto qualidade humana, a criatividade deve ser estudada a partir do ponto de vista dos sujeitos envolvidos, ou seja, aquilo que um indivíduo descobriu é novo e não importa se em outro lugar do mundo alguém descobriu a mesma coisa. A novidade pode ser grande ou modesta, como alguém que inventou algo muito útil ou uma criança que acaba de fazer seu desenho.

\section{Atributo e processo}

A criatividade é um fenômeno com múltiplas facetas e é por isso que desafia uma definição precisa (TORRANCE, 1988). A criatividade é descrita, ao mesmo tempo, como um atributo e como um processo que se verifica e se desenvolve no nível do indivíduo e da sociedade (DE MASI, 2002/2003; GALVÃO, 1999). Observa-se como nas crises e guerras surgiram grandes invenções. Nesse sentido, relembra-se que a crise traz progresso. A respeito disso, Menchén-Bellón (2015) comenta que a criatividade nasce da angústia como o dia nasce da noite escura. $\mathrm{Na}$ crise, nasce a invenção, as descobertas e as grandes estratégias.

Nessa direção, valor é um tema evasivo e subjetivo. De acordo com Rodríguez-Estrada (2008), em termos gerais, pode-se distinguir três graus ou níveis para avaliar o produto: I. O produto é valioso para o círculo afetivo do sujeito criador; II. É valioso para seu meio social; III. É valioso para a humanidade. A seguir, apresentam-se, de forma gráfica (Figura), os três graus para avaliar um produto.

Pode-se considerar que existem três níveis de criação: I. O nível elementar ou de interesse pessoal e familiar; II. O nível médio ou de ressonância laboral e profissional; III. O nível superior ou da criação transcendente o universal. A definição exata do que é criatividade se torna um fator muito complexo pela existência de diversos parâmetros que devem ser analisados. Existem muitos ti- 
pos de definições e linhas de estudos - o conceito de criatividade se une a fatores cognitivos, fatores psicológicos (associado à capacidade, aos modelos de pensamento, às competências de cada indivíduo, ao domínio do pensamento), fatores motivacionais (intrínsecos e orientados a tarefas), fatores de personalidade (autoeficácia, capacidade de arriscar, de desafiar, entre outros), fatores ambientais e fatores sociais, além de interesse pelo apoio e estímulo à criatividade.

Figura - Graus ou níveis para avaliar um produto.

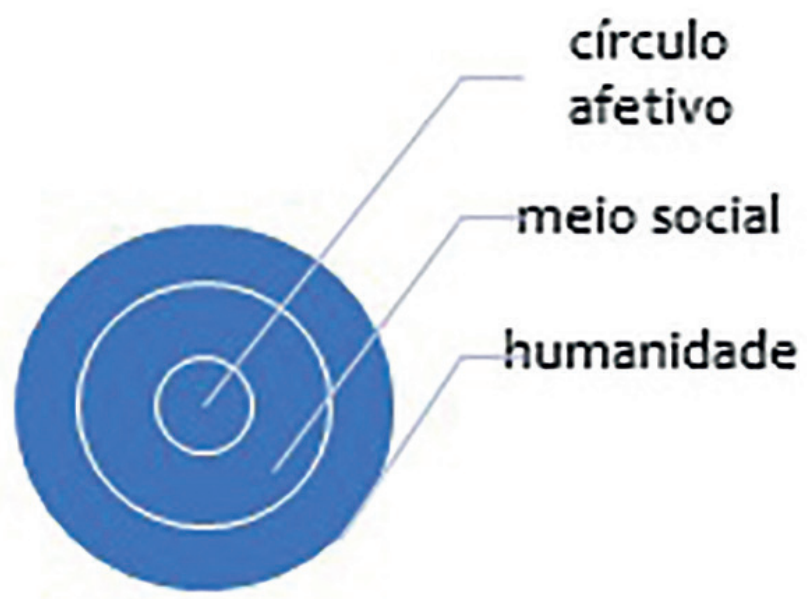

Fonte: elaborado com base em Rodríguez-Estrada (2008).

Apesar de, muitas vezes, a criatividade ser conceituada como algo impossível de ser definido, inserindo-se em um campo complexo de entendimento, e de seus atos criativos não seguirem uma frequência previsível, muitos estudos são realizados pela necessidade e importância que a criatividade tem na sociedade desde seu primórdio até o período atual (FABRETE, 2015). De acordo com Seabra (2008), "talento", "genialidade", "prodígio" e "sobredotação" são termos que competem para definir o mesmo fenômeno: a capacidade de resolver problemas de forma original e produzindo um resultado útil e valioso. A criatividade tem uma vertente integradora porque tenta aglutinar no processo educativo o desenvolvimento total do ser humano. Por várias razões, ela é uma fonte fundamental de sentido à vida (MENCHÉN-BELLÓN, 2015).

A criatividade se torna tão fascinante por duas razões: em primeiro lugar, a maioria das coisas interessantes, importantes e humanas são resultado da criatividade. A segunda razão é que, quando se entrega a ela, sente-se que se está vivendo mais plenamente que durante o resto da vida (HÁSIKSZENTMIHALYI, 1998). Na mesma perspectiva, Robinson (2009) alerta repetidas vezes que, quando se desfruta fazendo aquilo que mais se gosta, alcança-se a máxima qualidade 
na tarefa, ao mesmo tempo que se está desenvolvendo a criatividade. O problema é que não se é consciente dos próprios talentos e inclinações naturais. A respeito disso, alguns princípios básicos que ajudem a avançar para um futuro mais sustentável e mais próspero são esboçados por Florida, Mellander e Stolarick (2011), os quais são listados a seguir.

Um primeiro princípio é que todos os seres humanos, sem exceção, são criativos. A verdadeira chave do crescimento econômico se encontra em aproveitar plenamente o talento criativo que há em todos. Um segundo princípio é que é preciso criar bons postos de trabalho, e em grande quantidade. Um terceiro princípio é a necessidade de reformar o sistema educativo. Precisa-se de um sistema de aprendizagem e de desenvolvimento alinhado com a nova economia criativa.

Um quarto princípio é que é preciso de um novo contrato social. Um quinto princípio é que se necessita construir a infraestrutura do futuro, e não se limitar à do passado. Por tudo isso, destacar a dimensão da criatividade na educação implica promover, principalmente, atitudes criadoras, dinamizando as potencialidades individuais, favorecendo a originalidade, a apreciação do novo, a inventividade, a expressão individual, a curiosidade e a sensibilidade diante dos problemas, a receptividade no tocante às novas ideias, à percepção e à autodireção (FABRETE, 2015; SILVA, 2014).

Nesse sentido, atrever-se a ser criativo requer uma grande curiosidade como Leonardo da Vinci, que tinha um caderno no qual anotava tudo; exige ter uma grande paciência e fé como Thomas Edison, que para fabricar a lâmpada elétrica teve de passar por 999 experiências que fracassaram; e outro atrevimento seria saber olhar a realidade como se estivesse aprendendo a ver o mundo como fez Picasso (MENCHÉN-BELLÓN, 2012).

\section{O processo criativo}

Considerando o processo criativo, há um consenso de que ele ocorre prioritariamente envolvendo questões com as quais já existe um grau de envolvimento e esforço mental, em vez de ser produto de um pensamento repentino, totalmente desvinculado do assunto a que se aplica (PINHEIRO, 2009). Dos estudos realizados, nomeadamente por Guilford (1950), conforme apontado anteriormente, três conclusões foram aferidas que são pontos fundamentais para as discussões levantadas neste artigo: 1) Todos, sem exceção, possuem potencial criativo; 2) O potencial é independente de idade, gênero, raça ou condição social; 3) O potencial pode ser descoberto e desenvolvido pela ação de uma pedagogia apropriada (JAOUI, 1995).

Nesse sentido, Rhodes (1961) propôs um modelo que apresenta quatro referências recorrentes no ato criativo: Press (ambiente ou contexto), Person (pessoa criativa), Process (processo criativo) e Product (produto criativo), cujo 
conhecimento da forma como se conjugam, no espaço escolar, poderá estabelecer as condições favoráveis à promoção da criatividade e à expansão do conhecimento por parte do indivíduo. Essas quatro referências recorrentes no ato criativo são chamadas por Money (1963, p. 81) de facetas. Ele afirma que "o problema da compreensão da criatividade depende de quatro facetas diferentes daquelas que a pessoa pode estar implicada de forma distinta". Todos têm uma concepção implícita de criatividade que faz referência a uma ou várias facetas.

$\mathrm{Na}$ mesma direção, Kneller (1978, p. 15) reconhece em seus estudos quatro dimensões em que a criatividade está inserida:

Ela pode ser considerada do ponto de vista da pessoa que cria, isto é, em termos de fisiologia e temperamento, inclusive atitudes pessoais, hábitos e valores. Pode também ser explanada por meio de processos mentais - motivação, percepção, aprendizado, pensamento e comunicação - que o ato de criar mobiliza. Uma terceira definição focaliza influências ambientais e culturais. Finalmente, a criatividade pode ser entendida em função de seus produtos, como teorias, invenções, pinturas, esculturas e poemas.

Para Chaffe (2000), viver a vida de forma criativa significa levar os talentos criativos e a capacidade de pensamento criativo a todas as dimensões da vida. Na mesma direção, Seabra (2008, p. 3) afirma que "na verdade, exprimimos criatividade todos os dias, desde o momento em que acordamos até àquele em que adormecemos". De acordo com Ribeiro (2015), as características da criatividade, segundo a literatura, são: capacidade de solucionar problemas; fluência; pensamento por metáforas; originalidade; concentração; autorrealização; elaboração; inovação; perspectiva incomum; fantasia; emoção; pensamento por analogias; inconformismo; impulsividade; confiança em si; persistência; energia; liderança; visionário; otimismo; tolerância à frustração.

Com a intenção de apontar algumas justificativas para que se promova uma educação criativa, será apresentado a seguir um pequeno texto, que é o testemunho de uma mãe sobre como educa sua filha, procurando desenvolver seu potencial criativo. Ela afirma:

Educar uma criança é um desafio, tanto física quanto mentalmente, pois exige muita criatividade. Como mãe solteira, tento técnicas diferentes para incentivar a minha filha, pensando em novas e diferentes maneiras de manter a sua concentração durante os estádios iniciais de aprendizagem. Por exemplo, para todos os meses do ano e todos os dias da semana há um conto, já que eu enfeito o assunto com histórias para aumentar a sua aprendizagem. Brinco com ela fingindo ser a filha e ela a mãe, o que me ajuda a entender como ela me vê como mãe, e proporciona-lhe uma oportunidade de expressar os seus sentimentos. Tento estimular a sua criatividade (e preser- 
var a minha sanidade) fazendo-a participar no processo de cozinhar. Dou-lhe casca de legumes e uma panela para que ela possa preparar a sua própria "sopa". Recortamos fotografias de catálogos com móveis, tapetes e cortinas e ela cola-as em caixas de papelão, criando a sua própria decoração de interior [...]. A criatividade é um impulso instintivo meu que direcionou para ela de muitas maneiras: sou uma costureira para a Festa das Bruxas, uma conselheira nas horas de angústia, uma enfermeira para os acidentes inevitáveis da vida, uma organizadora de festas, um chef gourmet, uma professora ganhadora de prêmios e, sobretudo, uma amiga (CHAFFEE, 2000, p. 79).

Nesse trecho, a mãe conta como educa sua filha, procurando desenvolver a criatividade a partir de estímulos, procurando "técnicas diferentes" e "novas e diferentes maneiras" e tentando "estimular sua criatividade". Nesse caso, são as atividades que ela realiza com a filha, como as histórias contadas diariamente, as brincadeiras nas quais invertem os papéis de mãe e filha, a participação da filha no processo de cozinhar, a atividade de decoração, entre outras.

Ao verificar algumas ações da mãe, a partir dos verbos que ela conjuga em seu texto, encontram-se: incentivar, pensar, manter, enfeitar, aumentar, brincar, fingir, proporcionar, expressar, estimular, participar, cozinhar, recortar, colar, criar, entre outros, todos vinculados à criatividade, à intenção e ao compromisso de educar. A respeito disso, no livro "Manual de métodos criativos", o autor alemão Joachim Sikora declara que, em um simpósio sobre criatividade, os pesquisadores ali presentes associaram mais de 400 significados diferentes ao termo criatividade. E são muitas as ações que podem ser implementadas para desenvolver o potencial criativo.

\section{O ambiente criativo}

Primeiramente, considera-se de extrema relevância levantar discussões em torno do ambiente ou contexto em que se desenvolve o potencial criativo. Nesse sentido, acredita-se que uma fonte importante para aprender a pensar são os estudos na escola. Aprende-se a formular perguntas para sondar o ambiente; a buscar informação; a que tipo de ideias prestar atenção e como pensar sobre elas. Sobre esse tema, Rodríguez-Estrada (1995, p. 16) afirma que "se alguém não manifesta criatividade é porque deixou atrofiar (ou seus pais ou professores atrofiaram suas potencialidades)". Assim, vê-se a responsabilidade dos pais e da escola nesse processo. Ao não desenvolver, estimular, motivar, criar condições... está-se atrofiando, o que é realmente muito grave.

Robinson (2015) desenvolve sua teoria sobre a escola, especificamente acerca do papel destrutivo da criatividade que a escola exerce sobre as crianças. Ele considera que a figura do docente é determinante para conseguir que o aluno fomente a criatividade em seu centro educativo, pois o professor tem que 
potencializar o talento, não só priorizar os resultados finais, e ainda permitir o erro, pois dos erros se aprende. "A escola deve acolher, criativamente, os alunos e dar-lhes, a todos, a oportunidade de mostrarem o que valem, com vista à sua formação integral” (MARTINS, 2000, p. 85).

$\mathrm{Na}$ mesma direção, Boccolini (2016) afirma que é necessário que os professores se atrevam a desafiar a rotina do trabalho diário, que gerem ambientes sensoriais, de comunicação, em que os alunos se sintam acolhidos, estimulados para expressar suas ideias, seus pensamentos, suas emoções, seus sentimentos, e que isso seja assumido como parte do processo de aprendizagem. Essa autora (2016) ainda destaca a frase dita por Dewey: "se ensinamos os alunos de hoje como ensinávamos ontem, estamos lhes roubando o futuro".

Carnaz (2013) propõe que a escola deve promover a flexibilidade, a abertura à novidade, a capacidade de adaptação, novas formas de ver e realizar as tarefas, a coragem para enfrentar o inesperado. Philip Gammage propõe, segundo Craft (2000), que a educação não deveria focalizar "answering the question", e sim enfatizar "questioning the answer". Dessa forma, o que o autor propõe é que a educação, em vez de estimular a escrever uma única resposta, deveria incentivar a encontrar as perguntas, ou seja, em uma aula de matemática, por exemplo, no lugar de perguntar qual é o resultado de 5+5, que é igual a 10 invariavelmente, deveria perguntar quais números somados poderiam resultar em 10 . Dessa forma, há múltiplas respostas, e isso é estimulante para o aluno.

Por outro lado, a natureza misteriosa e/ou desconhecida da criatividade, a associação da criatividade à indisciplina, desobediência ou comportamentos desviantes, a assunção errônea do abandono de regras e princípios são ideias preconceituosas, fundamentadas no desconhecimento que impedem o objetivo essencial da promoção da criatividade na escola. Nessa direção, aponta-se a necessidade de um compromisso dos docentes, gestores e envolvimento de toda a comunidade escolar, no sentido de ressignificar esses conceitos, extinguindo esses aspectos negativos e prejudiciais. Algumas características propiciadoras de uma atmosfera criativa na sala de aula são elencadas no Quadro 1, com base em Alencar (1992). Embora apontadas há quase três décadas, percebe-se que continuam vigentes.

Entretanto, cabe salientar que não só a escola, mas também as famílias, principalmente os pais, têm o dever de potencializar a criatividade dos filhos. Voltando os olhos ao Quadro 1 e trocando a palavra "aluno" por "filho" ou "filha", são descobertas características propiciadoras de uma atmosfera criativa em casa. Cabe apontar que Dewey na escola teve uma educação desinteressante e desestimulante, o que foi compensado pela formação que recebeu em casa. Seu interesse pela Pedagogia nasceu da observação de que a escola de seu tempo continuava, em grande parte, orientada por valores tradicionais, e não havia incorporado as descobertas da Psicologia, nem acompanhara os avanços políticos e sociais (DEWEY, 2003). 
Quadro 1 - Caraterísticas propiciadoras de uma atmosfera criativa na sala de aula.

\begin{tabular}{|c|c|}
\hline $\begin{array}{l}\text { - Dar oportunidade ao aluno para levantar ques- } \\
\text { tões, testar hipóteses, discordar, propor interpreta- } \\
\text { ções e avaliar criticamente. } \\
\text { - Dar tempo ao aluno para pensar e desenvolver } \\
\text { as suas ideias. } \\
\text { - Criar um ambiente de respeito e aceitação mútuas. } \\
\text { - Estimular no aluno a habilidade de explorar conse- } \\
\text { quências para acontecimentos incomuns e futuristas. } \\
\text { - Encorajar os alunos a refletir sobre o que gosta- } \\
\text { riam de conhecer melhor. } \\
\text { - Desenvolver nos alunos a habilidade de pensar } \\
\text { em termos de possibilidade e aperfeiçoamento. }\end{array}$ & $\begin{array}{l}\text { - Promover o desejo de arriscar, de experimentar } \\
\text { e de manipular. } \\
\text { - Valorizar o trabalho do aluno, suas contribuições } \\
\text { e suas ideias. } \\
\text { - Encorajar o aluno a escrever poemas e histórias. } \\
\text { - Proteger o trabalho criativo do aluno da crítica } \\
\text { destrutiva dos pares. } \\
\text { - Estimular a aplicação dos princípios de geração } \\
\text { de ideias. } \\
\text { - Adaptar, modificar, substituir, rearranjar e combinar. } \\
\text { - Aceitar a espontaneidade, a iniciativa e o senso } \\
\text { de humor. } \\
\text { - Não se deixar vencer pelas limitações do contex- } \\
\text { to, pelas dificuldades de recursos ou pelas barreiras. }\end{array}$ \\
\hline
\end{tabular}

Fonte: Alencar (1992).

Além disso, atividades como esportes, artes, fotografias, visionamento de filmes, criação e uso de jogos, músicas, passeios, entre outros, estimulam a criatividade e devem ser utilizadas, dentro das possibilidades, no contexto escolar e familiar. A escola e a família devem sempre atuar em parceria, uma apoiando a atividade da outra. Nessa direção, as atividades enviadas para a casa e extracurriculares também devem ser vistas como oportunizadoras de desenvolvimento do potencial criativo. Nessa perspectiva, atividades criativas geram motivação, não o tédio e o enfado. Deve-se buscar o equilíbrio para não sobrecarregar as crianças e os adolescentes e aproveitar bem o tempo do qual eles dispõem.

Destaca-se que as atividades precisam ser diversificadas. Nesse tempo de constante mudança e grande quantidade de informação proporcionada pelas tecnologias, principalmente a partir do acesso à internet, é preciso ter em mente que os educandos necessitam de orientação, pois não têm maturidade para, por si mesmos, filtrar e selecionar o que é importante, adequado e útil. Nesse sentido, Florida (2010) explica como na atualidade se vive em uma sociedade que só parece valorizar o acesso à informação e ao conhecimento, quando o que realmente tem valor econômico é o que a criatividade humana é capaz de fazer com tudo isso.

Se, por um lado, vive-se o desafio de combater a falta de informação, é preciso também, por outro lado, combater as informações falsas, que são frequentes. Porém, ainda mais desafiador é converter os meios de comunicação em aliados no processo do desenvolvimento do potencial criativo; não só a internet, mas televisão, rádio e jornais, entre outros, devem ser vistos como importantes ferramentas para uma educação criativa. E ainda, muitos exercícios, jogos e textos criativos propostos neste artigo para o contexto escolar podem ser usados no contexto familiar, fomentando o estímulo à criatividade. 
Embora atualmente se reconheça a grande importância do pensamento criativo, não é possível dizer que no sistema de ensino o pensamento criativo seja estimulado e/ou reforçado. Vários fatores estão na origem desse problema, desde a própria formação dos professores, até o tempo limitado para que sejam efetuadas determinadas aprendizagens, deixando pouco tempo para atividades livres e criativas. A respeito disso, Carnaz (2013, p. 14) afirma que

à medida que a criança cresce e avança na sua escolaridade, maior preponderância é dada às suas competências intelectuais, em detrimento da sua criatividade. Quase sem querer, a maioria das crianças deixa de se dedicar a atividades meramente criativas, das quais é exemplo o simples desenho livre.

Na mesma direção, Robinson (2015) reflete por que há tantas aulas de matemática e tão poucas (ou nenhuma) aula de dança nas escolas. A matemática é importante, mas a dança também.

Por outra parte, a criatividade implica ainda trabalhar o espaço físico e conceitual da sala de aula: se as crianças vão ser encorajadas a pensar autonomamente, em qualquer área do currículo, elas precisam ter acesso a materiais (livros, atlas, computadores, jogos) e espaço para trabalhar individualmente, em pares ou em grupo. A respeito disso, percebe-se que para as crianças menores, em jardins de infância e pré-escola, talvez em faixas etárias de até 9 ou 10 anos, as salas são coloridas e bem atrativas. À medida que os educandos crescem, as salas geralmente são de cor branca ou gelo, com as carteiras dispostas em fila; em muitas salas sequer há algum objeto ou mural na parede; e assim se vai reproduzindo a escola do século XIX, em pleno século XXI.

A respeito disso, Aparici e Silva (2012, p. 52) afirmam que

há mais de quarenta anos, Porcher (1976) já questionava que as escolas preparam os estudantes para se desempenharem em um mundo que já não existe. Esta situação foi se agravando com o passar dos anos, a tal ponto que é possível falar de uma concepção de "escola museu" onde se reproduz a cultura de "toda a vida" e uma concepção de escola fora das salas de aula e da cultura escolar.

Referindo-se à educação no contexto universitário, Stevenson (2015) aponta que hoje, mais do que nunca, esse âmbito tem que estar preparado e atento às demandas da sociedade. Dificilmente os jovens poderão encontrar respostas a problemas se só lhes são oferecidas ideias, ferramentas e metodologias próprias do século passado. Sabe-se que o que funcionou bem na geração de seus pais costuma funcionar mal na atual e o que serve hoje talvez não sirva aos futuros filhos. O grande problema nesse sentido é que professores estão preparando os 
alunos para atuar em um mundo no qual não se sabe como será. Esse é mais um motivo para que hoje se faça um compromisso em potencializar a criatividade nos alunos. É possível que, assim, vivendo de um modo criativo, o estudante esteja preparado para quase tudo.

Com a intenção de "facilitar o processo", muitos professores desenvolvem metodologias nas quais entregam tudo mais fácil para o aluno. Embora os alunos gostem do professor que explica tudo, Burke (2003) revela que isso pode ser muito ruim para eles. Quando os professores fazem pelo aluno a maior parte do trabalho mental, eles roubam do aprendiz justamente o que é mais fundamental em todo o processo. Em contrapartida, quando os professores estimulam seus alunos a fazer a maior parte do trabalho, a exercer as mais variadas atividades mentais, estão proporcionando a oportunidade de assimilarem e construírem seus novos conhecimentos e, concomitantemente, desenvolvendo o que lhes será mais útil pelo resto de suas vidas: a capacidade de aprender por conta própria, de pensar com a própria cabeça.

A reunião de competências cognitivas, como flexibilidade, fluência, imaginação e expressividade, é o alicerce para o pensamento criativo. A escola pode estimular a criatividade se promover uma aprendizagem construtiva, cooperativa e significativa; se utilizar critérios que valorizem a expressividade e originalidade; se recorrer ao conhecimento dos diversos domínios; se utilizar os processos de memorização como meio, e não como fim; se valorizar a compreensão; se aplicar e combinar métodos criativos (CARNAZ, 2013).

Por outro lado, no campo pedagógico, está-se em um período de valorização das vertentes educacionais que incentivam o estudante a se tornar protagonista de sua aprendizagem. Criar, construir, conceber, desenvolver, montar, combinar, projetar, testar, avaliar, revisar, tudo isso vem gradativamente se tornando verbos utilizados nos objetivos de aprendizagem dos planos de aula dos docentes e que elucidam que tipo de estudante se deseja desenvolver.

Multiplicam-se nas escolas as iniciativas que usam a abordagem fundamentadas em projetos, aprendizagem com base em problemas, práticas alinhadas ao design thinking e mais recentemente a influência do movimento maker, que valoriza a cultura do faça você mesmo (RAABE et al., 2016). Portanto, as metodologias ativas nas quais o estudante realiza as atividades em casa e as leva para as aulas são atividades que potencializam a criatividade e requerem um engajamento entre família e escola. A respeito disso, Moran (2000, p. 125) afirma que

os alunos levam para casa os textos, onde aprofundam a sua leitura, fazem novas sínteses, colocam os problemas que os textos suscitam, os relacionam com a sua realidade. Essa pesquisa é comunicada em classe para os colegas e o professor procura ajudar a contextualizar, a ampliar o universo alcançado pelos alunos, a problematizar, a descobrir novos significados no conjunto das in- 
formações trazidas. Esse caminho de ida e volta, onde todos se envolvem, participam é fascinante, criativo, cheio de novidades e de avanços. O conhecimento que é elaborado a partir da própria experiência se torna muito mais forte e definitivo em nós.

Nesse sentido, Loveless e Williamson (2017) aponta que existem estreitas semelhanças entre as qualidades dos processos criativos e a implicação e as demandas da aprendizagem na era digital, em que as pessoas devem lidar com questões, problemas, fracasso e decepção, para aprender dessas experiências e demostrar perseverança, resiliência e disposição em buscar soluções mais inventivas. Rodríguez-Estrada (2006) assinala que a criatividade é por si mesma motivadora. Qualquer situação e qualquer objetivo, enfocados criativamente, tornam-se interessantes, atrativos e apaixonantes. Nos últimos anos, a criatividade tem se tornado uma política educativa governamental como parte de um intento de “dotar de um novo encanto" a escolarização (HARTLEY, 2006, p. 85).

Robinson (2010) salienta a necessidade de reconhecer que a criatividade e a inovação passam por "fazer algo" frequentemente por parte de pessoas que estão apaixonadamente imersas em "seu elemento", em diferentes campos e com diferentes materiais. "Seja qual for a tarefa, a criatividade não é só um processo mental interno: implica ação. De certo modo, é imaginação aplicada" (ROBINSON, 2001, p. 115). No estímulo à criatividade dos educandos, os professores devem estar dispostos a atuar em diferentes papéis. Apresenta-se a seguir o Quadro 2, no qual é possível observar os papéis dos professores na educação criativa.

Quadro 2- Papéis dos professores no desenvolvimento da educação criativa.

\begin{tabular}{|l|l|}
\hline $\begin{array}{l}\text { - Papel de mentor: compreensão de si mesmo e } \\
\text { dos outros, comunicação eficaz e desenvolvimento } \\
\text { dos educandos. }\end{array}$ & $\begin{array}{l}\text { Papel de diretor: estabelecimento de metas e ob- } \\
\text { jetivos, planejamento e organização. }\end{array}$ \\
\hline $\begin{array}{l}\text { - Papel de facilitador: construção de equipes, uso } \\
\text { do processo decisório participativo e administra- } \\
\text { ção de conflitos. }\end{array}$ & $\begin{array}{l}\text { Papel de produtor: fomento de um ambiente pro- } \\
\text { dutivo, gerenciamento do tempo e do estresse. }\end{array}$ \\
\hline $\begin{array}{l}\text { - Papel de monitor: monitoramento de desempe- } \\
\text { nho individual, gerenciamento do desempenho e } \\
\text { processos coletivos e análise de informações com } \\
\text { pensamento crítico. }\end{array}$ & $\begin{array}{l}\text { - Papel do negociador: negociação de acordos e } \\
\text { compromissos e apresentação de ideias. }\end{array}$ \\
\hline
\end{tabular}

Fonte: adaptado de Quinn (2003, p. 200).

De acordo com Fabrete (2015), o trabalho de estímulo à criatividade em grupo apresenta resultados muito mais satisfatórios do que os individuais, pois é por meio de grupos que surgem ideias diversificadas. Aznar (2011, p. 215), em seus estudos, apresenta 41 exercícios (Quadro 3) que podem ser aplicados para estimular a criatividade. 
Quadro 3 - Exercícios para estimular a criatividade.

\begin{tabular}{|c|c|}
\hline Tipo de exercício & Tipo de técnica \\
\hline Exercício para dar a largada & $\begin{array}{l}\text { Apelidos de infância } \\
\text { Fórum } \\
\text { Falar com números } \\
\text { Rearranjo do espaço } \\
\text { Torniquete } \\
\text { Sim/não } \\
\text { Ombro a ombro }\end{array}$ \\
\hline Exercícios que facilitam a coesão do grupo & $\begin{array}{l}\text { Escultura humana } \\
\text { Pedra } \\
\text { Máquina viva } \\
\text { Espaço apertado } \\
\text { Aplausos } \\
\text { Maestro } \\
\text { Entrando no grupo }\end{array}$ \\
\hline Exercícios de relaxamento e expressão corporal leve & $\begin{array}{l}\text { Descontração } \\
\text { Toque dos dedos } \\
\text { Ninando } \\
\text { Levitação } \\
\text { Flor de lótus }\end{array}$ \\
\hline Exercícios corporais e treinamento do mecanismo associativo & $\begin{array}{l}\text { Bastões } \\
\text { Espelho } \\
\text { Passagem de gestos } \\
\text { Desequilíbrio } \\
\text { Movimento contínuo }\end{array}$ \\
\hline Técnicas de expressão criativa & $\begin{array}{l}\text { Poema em grupo } \\
\text { Jornal mural } \\
\text { Ritmos } \\
\text { Som de grupo } \\
\text { Expressão gráfica }\end{array}$ \\
\hline Exercícios de treinamento do mecanismo projetivo & $\begin{array}{l}\text { Inventar uma personagem } \\
\text { Analogias pessoais } \\
\text { Playback }\end{array}$ \\
\hline Exercícios envolventes & $\begin{array}{l}\text { Gosto mais, gosto menos } \\
\text { Quem é você? } \\
\text { Expressão emocional } \\
\text { Presentes } \\
\text { Salto do anjo }\end{array}$ \\
\hline
\end{tabular}

Fonte: adaptado de Aznar (2011).

\section{Uma proposta criativa}

Um modelo de educação a ser seguido é o da Finlândia. Mesmo sendo considerado um dos melhores sistemas de ensino do mundo há duas décadas, 
pode-se verificar que continua em constante reforma. De acordo com Cristo (2017), nos últimos anos entrou nas escolas uma maior diversidade de opções pedagógicas, na qual a tecnologia passou a fazer parte da aprendizagem em todas as disciplinas, então a ênfase recaiu sobre sete competências transversais, e a multidisciplinaridade tornou-se a obrigatória. Em 2017, fizeram a maior reunião de pais e professores do mundo. A meta era envolver os pais em um amplo debate sobre a agenda que os finlandeses acreditam ser necessária para preservar o nível de excelência do ensino público nos próximos anos.

$\mathrm{Na}$ mesma perspectiva, os finlandeses já se perguntavam: que tipo de conhecimentos, habilidades e aptidões serão importantes para um aluno em 2030 ? Eles querem um diálogo de alto nível e permanente sobre os fundamentos da educação do futuro. Nesse sentido, Saku Tuominenum, diretor do projeto HundrEd, criado no país para identificar e compartilhar inovações educacionais em todo o mundo, afirma: "E mais do que nunca precisaremos de soluções criativas em consonância com a base do pensamento finlandês, que é uma educação em que o aluno tenha prazer em aprender" (WALLIN, 2017, s/p).

Em relação ao espaço físico, nas escolas finlandesas as paredes vêm sendo derrubadas para a criação de espaços de ensino em plano aberto, com divisórias transparentes. Em vez das carteiras escolares, o mobiliário inclui sofás, pufes e bolas de pilates, tendo em vista que, no futuro, não haverá necessidade de salas de aula fechadas, e a aprendizagem acontecerá em todos os lugares (WALLIN, 2017); mas não se trata de espaços totalmente abertos, mas sim de áreas de estudo flexíveis e modificáveis (PICHEL, 2017).

Assim, observa-se que comprometer-se com uma educação de qualidade, que se abre para a criatividade, requer abertura às mudanças e atualizar-se constantemente. Marina e Pombo (2013, p. 45) indicam que a aprendizagem da criatividade forma parte da educação do talento.

A criatividade é a faculdade que nos permite sobreviver e progredir em um ambiente em movimento e acelerado [...]. Não estamos nos referindo só à criatividade artística, senão à capacidade para descobrir metas, resolver problemas, inventar saídas quando parecem que não existem, evitar a rotina, o tédio, a desesperança.

Segundo a literatura, são fatores da criatividade: tarefas desafiadoras; experiências positivas; apoio de superiores; estímulos intelectuais; ambiente físico com recursos; recursos tecnológicos (RIBEIRO, 2015).

\section{A escrita criativa}

Aponta-se a relevância da escrita criativa. Sabe-se que muitos produtos, como cursos presenciais, cursos on-line, e-books, vídeos e palestras, torneios, 
entre outros, têm sido vendidos com o nome de escrita criativa, principalmente nos últimos anos. Talvez a grande demanda para esse mercado seja por falta de um trabalho sério nas escolas em relação à escrita criativa no decorrer dos anos. De acordo com Taborda, citado por Pereira (2000 apud CARNAZ, 2013, p. 31), "criatividade nunca deverá confundir-se com produção incontrolada de automatismos ou com acumulações incongruentes de formas intelectualmente rudimentares". A escrita criativa é uma das dimensões da didática da escrita e, por isso, deve estar em concordância com as outras dimensões restantes, isto é, com o conhecimento sobre os textos, as técnicas de escrita etc. (CARNAZ, 2013).

Moura (2014) entrevistou professores e escritores portugueses, que apresentaram contribuições significativas aos temas, as quais serão relatadas de forma resumida a seguir.

Conceição García afirma que "usa técnicas para espicaçar e pôr as pessoas a escrever" (MOURA, 2014, s/p). Deixa claro aos alunos que "não há um só caminho" na escrita e revela que, para criar uma troca de autores e de leituras, em todas as aulas pede a um aluno que traga um conto à sua escolha.

Luís Carmelo pontua que a escrita criativa não é um remédio milagroso que se toma para se ser escritor. A ideia

não é formar escritores, mas leitores com competências. Aprendeu-se na escola primária a ler e a escrever. Aplicou-se de três ou quatro maneiras e acabou. Se se perceber que a linguagem é um jogo com os seus limites, mas que podem ser disputados, isso contribui para uma frescura imaginativa que depois se reflete noutros saberes (MOURA, 2014, s/p).

Pedro Chagas Freitas refere que "sempre que nos sentamos para escrever um texto estamos a fazer escrita criativa” (MOURA, 2014, s/p). Ele fala ainda

[...] de técnicas "muito lógicas", que não precisam de "alunos com determinado nível de formação"; e ainda de "jogos para desbloquear a singularidade de cada um", mas garante que não se trata de "ensinar a escrever livros", ou de "ensinar a ser criativo". "A pessoa já é criativa, já sabe ver as suas coisas de uma maneira muito própria. E isso é o que faz a diferença" (MOURA, 2014, s/p).

Rui Zink revela que "quem frequentar cursos de escrita fica menos mau escritor e pode ficar bastante melhor leitor” (MOURA, 2014, s/p). Ele afirma que

os cursos de escrita criativa foram inventados quando se inventou a escrita com Homero. "Todos os escritores tiraram um curso de escrita criativa": todos leram, trocaram impressões, compararam técnicas e trabalhos com outros escritores. "o curso é um círculo" e o orientador apenas "um distribuidor de jogo que se cala o mais pos- 
sível”, diz Zink. É neste círculo, antes das letras lançadas ao papel, que começa a escrita. "Escrever é ler, é estar atento, estar nas coisas. A parte da caneta e do papel, ou dos dedos no teclado, é apenas uma parte e muitas vezes a menos interessante" (MOURA, 2014, s/p).

Mário de Carvalho aponta que "é um largo conjunto de leituras que leva à escrita" (MOURA, 2014, s/p). Ele começou a escrever nos anos 1970, depois de ler uma data de livros de todo o tipo e de participar do grupo de leitura que se reunia em torno do professor Fernando Guerreiro para discutir livros.

É dos livros e de conversas como aquelas que nasce a literatura, diz. "Muitas das regras que nestes cursos se procuram aplicar mecanicamente, eu diria mesmo cegamente, são transgredidas pelos grandes autores. A literatura é uma arte de ambiguidades, de paradoxos, de incertezas, de instabilidade", diz para explicar porque não associa à escrita criativa as oficinas de escrita que orienta e onde não se alonga em exercícios (MOURA, 2014, s/p).

Já Luísa Costa Gomes não gosta que suas aulas sejam identificadas com a escrita criativa.

"Nunca me passou pela cabeça fazer um curso de escrita criativa",
diz. Orienta oficinas de escrita literária - é o termo que prefere - e
comunidades de leitores desde os anos 1990. A razão porque não
identifica aquilo que faz com a escrita criativa é achar que esta dis-
ciplina "põe uma ênfase desequilibrada na parte técnica, nos tru-
ques, nos esquemas e na maneira de fazer" (MOURA, 2014, s/p).

Assim como para a professora Luísa, infelizmente escrita criativa é uma expressão que não bem-aceita para muita gente. Moura (2014, s/p) explica que

[...] o jurado do Nobel da literatura, Horace Engdahl, disse em entrevista ao jornal francês La Croix que os cursos de escrita criativa e os contratos com as editoras estão a profissionalizar e empobrecer a literatura ocidental - "estes escritores, muitos deles formados em universidades europeias e norte-americanas, não transgridem nada porque os limites que eles próprios desenharam não existem". [...] o tema tinha sido lançado quando Hanif Kureishi, escritor e professor na Universidade de Kingston, no Reino Unido, afirmaram no Independent Bath Literature Festival que os cursos de escrita criativa, de que ele é professor, são "uma perda de tempo", já que "99,9\% dos alunos não têm talento".

As duas últimas entrevistas apontam problemas que devem ser vistos com atenção e merecem análise, pois talvez estejam enfocando demais nas técnicas, no saber fazer. Porém, salienta-se que a escrita criativa não visa formar escritores 
profissionais, mas sim tornar-se uma atividade potencializadora da criatividade e que os educandos desenvolvam o prazer na leitura e na escrita, uma vez que são inseparáveis: a leitura é uma parte fundamental da escrita. Estudiosos apontam que a relação entre ler e escrever é como a que existe entre ouvir e falar. A respeito da importância de desenvolver as habilidades leitoras, Borges sempre dizia que uma pessoa não é o que é pelo que ela escreve, senão pelo que ela leu (STEVENSON, 2015).

Com tudo até aqui, acredita-se que já há motivos mais que suficientes para fomentar uma educação criativa ou educar para a criatividade. São oportunidades de estimular a criatividade. Como diz o escritor português Pedro Chagas, são "jogos para desbloquear a singularidade de cada um”, mas não se trata de "ensinar a escrever livros, ou de "ensinar a ser criativo", pois "a pessoa já é criativa, já sabe ver as suas coisas de uma maneira muito própria. E isso é o que faz a diferença" (MOURA, 2014, s/p).

Stevenson (2015) pontua que é frequente iniciar-se na prática da escrita enquanto se busca um caminho que facilite a comunicação com o exterior, mas pode-se escrever para percorrer o caminho que leva a descobrir o mundo interior. Alguns escritores começam a escrever a cada manhã como se tratasse de um ritual sagrado; outros descrevem o momento como o de chegar a um bote salva-vidas ao qual poder subir quando tudo parece perdido. A escritura pode ser uma via de escape da vida cotidiana ou um entretenimento.

Os processos da escrita despertaram a curiosidade de cientistas e terapeutas, principalmente no mundo anglo-saxão, e, hoje em dia, aplicam-se com êxito determinadas práticas de escrita criativa em pacientes que sofrem de hipertensão ou Alzheimer.

Alejandra del Río, por exemplo, citada por Stevenson (2015), centra seu estudo na prática da poesia com fins terapêuticos. Ela destaca o efeito catártico e consolador desse gênero literário, pois escrevendo o paciente consegue livrar-se de emoções negativas e encontra consolo para suas dores; lendo se sente menos só em sua enfermidade e até pode encontrar novos caminhos para enfrentar as situações críticas. Escrever atua como fortalecedor do eu. Nesse sentido, ao estimular o gosto pela leitura e pela escrita, a partir de propostas de escrita criativa, está-se também instrumentalizando os educandos com ferramentas poderosas para enfrentar adversidades, enfermidades e problemas que poderão surgir ao longo de suas vidas. Por outro lado, fomentar a escrita criativa em lares de idosos e outros espaços para a terceira idade revela-se como preponderante, tendo em vista que há tantos benefícios.

Como importante recurso em projetos de escrita criativa nas escolas ou comunidades, sugere-se o uso de portfólios físicos ou digitais ou até mesmo os dois tipos. Há muitas sugestões de tipos e formas de fazer um portfólio em sites e blogs na internet. Portfólio é um documento individualizado do processo 
de aprendizagem, organizado com propósitos definidos. Propõe uma seleção de evidências de aprendizagem e tem forte papel motivacional. Os portfólios físicos podem ser pastas totalmente prontas ou usar papel A4 e dar autonomia para o educando preparar sua pasta como julgar conveniente; mostrar exemplos irá ajudá-los nesse processo. Já os formatos digitais para portfólios podem ser: documentos de texto, apresentações de slides, blog, fórum restrito a uma plataforma virtual, sistema de pastas em plataforma virtual, plataformas virtuais específicas, entre outros.

Rodari (1982) e Condmarin e Chadwick (1987) dão algumas sugestões para estimular a escrita criativa, como completar parágrafos, realizar acrósticos, mímica, escrita em dupla, listas de palavras, trava-línguas, entre outras. Para Majaro (1988, p. 154), "uma pessoa criativa é normalmente capaz de gerar muitas ideias com grande rapidez em resposta a uma dada situação", tendo "muito mais dificuldades em apresentar respostas em virtude de um número muito mais reduzido de ideias perante o mesmo desafio". Ele apresenta cinco exercícios que, acredita, podem auxiliar na avaliação de candidatos: 1) Indique novas e diferentes aplicações para o clipes de papéis; 2) Desenvolva serviços adicionais que uma companhia de aviação possa oferecer aos passageiros em voo; 3) Faça uma lista de novos artigos que possam ser vendidos nas estações dos correios; 4) Indique partes da anatomia começadas com C; 5) Indique novas formas de combater o terrorismo.

Considera-se relevantes as opções de Majaro e pode-se pensar em muitas propostas análogas a essas. A seguir, apresentam-se algumas sugestões de escrita criativa elaboradas pelos autores deste artigo e outras adaptadas de Rodríguez-Estrada (1998, 2006):

- Os fabricantes de remédios, perfumes ou automóveis dedicam muito tempo a imaginar, inventar e aplicar novos nomes. O nome original e inovador é um valor apreciável e pode ter fortes implicações psicológicas. Pedir aos alunos que inventem (em duplas) nomes novos para: relógio, espelho, computador, cachorro, escada, carro, lâmpada, maçaneta.

- Escrever um texto usando todas estas palavras: vida, tristeza, amizade, esperança, saudade, canto, pássaros (criar outros textos a partir dessa ideia).

- Com a técnica de colagem (com recortes de revistas ilustradas), elaborar individualmente um livreto sobre sua própria história, com o tema: "Amo muito tudo isso". Esse tema, conhecido por ser slogan do McDonald's, agrada os alunos. Também pode ser usado em aulas de línguas estrangeiras, traduzindo-se o tema e permitindo que os alunos consultem dicionários quando necessário.

- Técnica estranhamento do objeto: escolhe-se um objeto qualquer para descrever, isto é, para explicar como ele é, mas fazendo de conta que é algo estranho, por isso não se pode indicar o nome dele nem dizer claramente para que serve. Observando as características do objeto que 
podem ser percebidas pelos sentidos - cor, som, cheiro, sabor e textura - e usando a imaginação, oferecer dicas, pistas e informações indiretas para o leitor. $\mathrm{O}$ aluno poderá escolher o objeto que quiser ou por meio de sorteio, sem revelar aos demais. Ao final, o texto será lido, e os colegas tentarão descobrir o objeto.

- O professor mostra um cartaz com figuras, mas sem texto, e cada participante escreve uma história a partir do cartaz. Depois de ler, devem votar na mais interessante e original.

- Rebatizar, ou seja, pôr um novo e original título em três livros ou filmes famosos, comparando as ideias de cada participante e assinalando os mais criativos.

- Imaginar que um parente distante falece em Londres e deixa de herança 20 bilhões de dólares. Cada participante deve escrever o que faria em tal situação e ler o texto a todos.

- Com objetos variados tirados à sorte de dentro de uma caixa, construir uma história espontânea para escrever e partilhar. Colocar na caixa objetos diversos: borracha, telefone, agulha, caneta, relógio, boneca etc. $\mathrm{O}$ aluno pode escrever como se o objeto tivesse vida e em primeira pessoa.

- É anunciada uma greve dos empregados do zoológico, que se queixam de receber salários de fome e sofrer condições desumanas. Para pressionar, decidiram que deixarão escapar dois leões, criando um grande perigo para a cidade; isso será feito dentro de 48 horas. No dia seguinte a essa declaração dos líderes, os jornais locais trazem diversos artigos a respeito desse assunto. Os comentários vêm respectivamente: a) do governador; b) do chefe de polícia; c) de um economista; d) de um sociólogo; e) de um psicólogo; f) de um teólogo; g) de um eterno líder dos trabalhadores. Imaginar e escrever os sete artigos correspondentes.

- Escrever sobre o tema "A criatividade é uma atitude diante da vida", criando duas pequenas histórias. Fazer a leitura ao final ou na aula seguinte.

- Escrever todas as consequências e variações desta situação: por decreto superior, deixa de existir o Ministério de Educação e Cultura, bem como todas as Secretarias de Educação. Cada família fica em total liberdade de conduzir a educação dos filhos como achar melhor.

Por fim, a Revista Comunicar desde 1993 publica artigos nos quais apresenta expressivas contribuições no que se refere ao estímulo da criatividade. Propostas de trabalhos com jornais, desenho em quadrinhos, rádio, vídeos, televisão, anúncios publicitários, videoclipes, tabletes, telefones celulares, WhatsApp, uso de legendas, redes sociais, entre outras propostas, são apresentadas. Assim, salienta-se que essas propostas devem ser conhecidas e difundidas nos contextos em que se atua, caso se deseja comprometer com uma educação de qualidade. 


\section{Considerações finais}

De acordo com Bartolomé (1994, p. 95),

Criatividade indica sempre uma dimensão existencial, que utilizando integralmente todas as suas faculdades lógicas e emotivas tende a situar-se de maneira aberta e original em relação com o ambiente contra o conformismo e o nivelamento ao que a sociedade submete o homem de hoje. A criatividade reivindica o valor único, inviolável da pessoa, o valor de sua originalidade, de sua crítica contribuição ao diferente por uma melhora da própria sociedade.

Na mesma perspectiva, ao olhar à própria volta, observa-se que as oportunidades para exprimir a originalidade estão por todo o lado. É preciso usar a criatividade para melhorar a família, a escola, o bairro, o país. Sabe-se que cada pessoa tem um potencial criativo a ser desenvolvido e que os pais e/ou as escolas têm ignorado esse fato, favorecendo ambientes propícios ao tédio e ao desinteresse e, consequentemente, oportunizando o surgimento de outros problemas no ambiente escolar. As constantes modificações nas sociedades, principalmente a partir do uso das tecnologias de informação e comunicação, requerem novos saberes e atitudes.

As investigações apontam a necessidade de investir em uma educação que estimule a criatividade, que deve tornar-se uma meta não só dos professores, mas dos pais, trabalhando em parceria, e também de outros atores sociais. É possível estimular a criatividade com exercícios e atividades individuais e grupais. Neste artigo, foram apresentadas diversas sugestões que visam aportar orientações para aqueles que desejam iniciar ou descobrir outras formas criativas de trabalho.

Aponta-se como modelo de educação criativa o trabalho que realiza o sistema educacional da Finlândia, que se preocupa com currículo e conteúdos, com os ambientes de aprendizagem e com a união entre escola e família para o sucesso na aprendizagem. Outro ponto que se destaca na Finlândia é o respeito ao professor, revelado na formação e também no salário.

Apresentou-se ainda a escrita criativa como proposta legítima para o estímulo à criatividade. Nesse sentido, as entrevistas aos professores portugueses e os exemplos de exercícios de escrita e jogos criativos pretendem apontar que, sim, é possível trabalhar de forma criativa com poucos ou muitos recursos. Por outro lado, a proposta de utilizar portfólios ao desenvolver essas atividades conferem autonomia e autorregulação, além de acompanhamento e reflexão sobre os processos. Dessa forma, espera-se ter contribuído para ampliar a visão do que se pode fazer para estimular a criatividade nos ambientes familiar e escolar. 
Recebido em: 14/07/2019

Revisado em: 11/08/2019

Aceito para publicação em: 12/08/2019

\section{Notas}

1 Doutora em Comunicação pela Universidade de Huelva, na Espanha. Mestra em Linguística Aplicada pela Universidade de Brasilia (UnB). Professora, tutora virtual, investigadora na Universidade do Minho, em Portugal. Tradutora e consultora educacional. E-mail: lilyrocharibeiro@gmail.com 2 Doutor em Psicopedagogia pelo Universidade de Huelva, na Espanha. Professor titular da mesma universidade. E-mail: director@grupocomunicar.com

3 Doutora em Comunicação e Educação. Professora da Universidade de Santiago de Compostela, na Espanha. Professora em várias universidades espanholas e professora em universidades latino-americanas, entre elas Chile e Equador. Pesquisadora do Centro de Estudos do Ensino Superior da República Tcheca e revisora científica de revistas nacionais e internacionais. E-mail: mariccaldeiro@yahoo.es

\section{Referências}

ALENCAR, Eunice. Como desenvolver o potencial criador. Petrópolis: Vozes, 1992.

APARICI, Roberto; SILVA, Marcos. Pedagogía de la interactividad. Comunicar, v. 19, n. 38, p. 51-58, 2012. Disponível em: https://www.revistacomunicar. $\mathrm{com} /$ index.php?contenido $=$ detalles\&numero $=38 \&$ articulo $=38-2012-07$. Acesso em: 7 mar. 2019.

BARTOLOMÉ, Donaciano. Creatividad y medios de comunicación. Comunicar, v. 1, n. 2, p. 95-97, 1994.

BOCCOLINI, Amalia. ¿Hacia dónde va la escuela? Mochila digital: Reflexiones, ideas, herramientas y recursos para el educador del siglo 21, 16 jul. 2016. Disponível em: https://mochiladigitalsite.wordpress.com/2016/07/16/hacia-donde-va-la-escuela/. Acesso em: 7 mar. 2019.

BURKE, Thomas Joseph. O professor revolucionário. Petrópolis: Vozes, 2003.

CARNAZ, Maria Elisabete Alves Rosa. Da criatividade à escrita criativa. 2013. Dissertação (Mestrado em Didática da Língua Portuguesa) - Universidade de Coimbra. Coimbra 2013. Disponível em: https://comum.rcaap.pt/bitstream/10400.26/12238/1/ELIZABETE_CARNAZ.pdf. Acesso em: 7 mar. 2019.

CHAFFEE, John. Thinking critically: a concise guide. New York: Houghton/Mifflin, 2000. 
CRAFT, Anna. Creativity across the primary curriculum: framing and developing practice. London: Routledge, 2000.

CONDEMARÍN, Mabel; CHADWICK, Mariana. A escrita criativa e formal. Porto Alegre: Editora Artes Médicas, 1987.

COSTA, Carlos. O papel do docente hoje é fazer parceria com os alunos.

Revista Ensino Superior, 30 jun. 2015. Disponível em: https:/ /www.revistaensinosuperior.gr.unicamp.br/artigos/o-papel-do-docente-hoje-e-fazer-parceria-com-os-alunos. Acesso em: 7 mar. 2019.

CRISTO, Alexandre. Levar os alunos para o século XXI a Finlândia já o fez. Observador, 19 mar. 2017. Disponível em: https://observador.pt/especiais/ levar-os-alunos-para-o-seculo-xxi-a-finlandia-ja-o-fez/. Acesso em: 7 mar. 2019.

DE MASI, Domenico. Criatividade e grupos criativos. Rio de Janeiro: Sextavante, 2003.

DEWEY, John. Democracia e educação: introdução à filosofia da educação. Tradução de Godofredo Rangel e Anísio Teixeira. 4. ed. São Paulo: Nacional, 1979.

Democracy and Education: an introduction to the philosophy of education. Charlottesville: University of Virginia, 2003.

DOLLINGER, Stephen. Creativity and conservatism. Personality and Individual Differences, n. 43, p. 1025-1035, 2007. Disponível em: https://www. psychologytoday.com/files/u81/Dollinger_2007_.pdf. Acesso em: 7 mar. 2019.

EYSENCK, Hans. As formas de medir a criatividade. In: BODEN, Margaret (Org.). Dimensões da criatividade. Porto Alegre: Artes Médicas, 1999. p. 203-244.

FABRETE, Teresa C. Lopes. A influência das práticas pedagógicas docentes e das barreiras discentes sobre o desenvolvimento da criatividade do futuro administrador. 2015. Dissertação (Mestrado em Administração) - Universidade Metodista de São Paulo, São Bernardo do Campo, 2015.

FLORIDA, Richard. La clase creativa: la transformación de la cultura, el trabajo y el ócio en el siglo XXI. Barcelona: Ediciones Paidós, 2010.

FLORIDA, Richard; MELLANDER, Charlotta; STOLARICK, Kevin. Creativity and prosperity: The global creativity index. Toronto: Universidade de Toronto/Martin Prosperity Institute, 2011 Disponível em: https://tspace. library.utoronto.ca/bitstream/1807/80125/1/Florida\%20et\%20al_2011_Creativity $\% 20$ and $\% 20$ Prosperity.pdf. Acesso em: $1^{\circ}$ mar 2019. 
GALVÃO, Marcelo. Criativa mente. Rio de Janeiro: Qualitymark, 1999. GUILFORD, Joy. Creativity. American Psychologist, v. 5, n. 9, p. 444-454, 1950.

HARTLEY, John. Creative industries. New Jerswy: Wiley-Blackwell, 2006. JAOUI, Hubert. La Créativité. Paris: Editions Morisset, 1995.

KNELLER, George. Arte e ciência da criatividade. São Paulo: Ibrasa, 1978. LOVELESS, Avril; WILLIAMSON, Ben. Nuevas identidades de aprendizaje en la era digital: Creatividad. Educación. Tecnología. Sociedad. Madrid: Narcea Ediciones, 2017.

MARTINS, Vitor Manuel. Para uma pedagogia da criatividade: propostas de trabalho. Porto: Asa, Cadernos do CRIAP, 2000.

MARINA, Jose Antonio; POMBO, Alvaro. La creatividad literaria. Barcelona: Ariel, 2013.

MAJARO, Simon. Criatividade: um passo para o sucesso. Mem Martins: Publicações Europa-América, 1988.

MENCHÉN-BELLÓN, Francisco. La riqueza del tiempo libre. Cómo activar tu creatividad en el tiempo de ocio. México: Trillas. 2011.

- Atrévete a ser creativo: Pasos para ser creativos. Revista Iberoamericana sobre Calidad, Eficacia y Cambio en Educación, v. 10, n. 2, p. 248-263, 2012.

. La educación alternativa: La Escuela Galáctica. Revista Creatividad y Sociedad, n. 21, p. 1-25, 2013.

. Especular con la ceatividad en las organzaciones modernas. Revista Creatividad y Sociedad, n. 23, p. 100-126, 2015.

MORAIS, Maria de Fatima. Definição e avaliação da criatividade. Braga: Universidade do Minho, Instituto de Educação e Psicologia, 2001

MORAN, José. Mudar a forma de ensinar e de aprender. Revista Interações, São Paulo, v. 5, p. 57-72, 2000. Disponível em http://www.eca.usp.br/prof/ moran/site/textos/tecnologias_eduacacao/uber.pdf. Acesso em: $1^{\circ}$ mar. 2019. MOURA, Catarina. Onde para a escrita na escrita criativa? Ípsilon, 28 dez. 2014. Disponível em: https://www.publico.pt/2014/12/28/culturaipsilon/noticia/onde-para-a-escrita-na-escrita-criativa-1680305. Acesso em: 7 mar. 2019. 
NONAKA, Ikujiro; TAKEUCHI, Hirotaka. Criação do Conhecimento na Empresa: como as empresas geram a dinâmica da inovação. Rio de Janeiro: Campus, 1997.

ORTEGA Y GASSET, José. La rebelión de las masas. Madrid: Revista de Occidente, 1975.

OSTROWER, Foigo. Criatividade e processos de criação. 16. ed. Petrópolis: Vozes, 2002.

PICHEL, Mar. Como a Finlândia, país referência em educação, está mudando a arquitetura de suas escolas. BBC, 30 set. 2017. Disponível em: https:/ /www. bbc.com/portuguese/internacional-41422377. Acesso em: 7 mar. 2019

PINHEIRO, Igor. Modelo geral da criatividade. Psicologia: Teoria e Pesquisa, v. 25, n. 2, p. 153-160, 2009 Disponível em: http://www.scielo.br/pdf/ptp/ v25n2/a02v25n2. Acesso em: 7 mar. 2019.

PREDEBON, José. Criatividade: abrindo o lado inovador da mente. São Paulo: Atlas, 1997.

QUINN, Robert. Competências gerenciais: princípios e aplicações. Rio de Janeiro: Elsevier, 2003.

RAABE, André et al. Educação criativa: multiplicando experiências para a aprendizagem. Recife: Pipa Comunicação, 2016.

RIBEIRO, Olzeni Leite. Criatividade na expertise: implicações para processos de aprendizagem de alto nível. 2015. Tese (Doutorado em Educação) UCB, Brasília, 2015

ROBINSON, Ken. Out of our minds: learning to be creative. Chichester: Capstone Publishing Ltd., 2001.

bo, 2010

. El Elemento. Descubrir tu pasión lo cambia todo. Barcelona: Grijal-

Busca tu elemento. Aprende a ser creativo individual y colectivamente. Barcelona: Empresa Activa, 2012.

ROBINSON, Ken; ARONICA, Lou. Creative schools: revolutionizing education from the ground up. London: Penguin Books, 2015.

RHODES, Mel. An analysis of creativity. Phi Delta Kappan, v. 42, n. 7, p. 305-310, 1961.

RODARI, Gianni. Gramática da fantasia. Introdução à arte de contar histórias. São Paulo: Caminhos, 1982. 
RODRÍGUEZ-ESTRADA, Mauro. Mil ejercicios de creatividad clasificados. Buenos Aires: McGraw-Hill Interamericana, 1995.

. Psicologia de la creatividad. Ciudad de México: Editorial Pax, 2006. Pax, 2008. . Creatividad verbal: como desarrollarla. Ciudad de México: Editorial

ROMO, Manuela. Creatividad en los domínios artísticos y científicos, y sus correlatos educativos. In: MORAIS, Maria de Fátima; BAHIA, Sara (Coords.). Criatividade: conceito, necessidades e intervenção. Braga: Psiquilíbrios Edições. 2008. p. 65-90.

ROSA, Alexandra. Hoje é primavera em Paris e eu não posso vê-la. 8 abr. 2014. Disponível em: https:/ / caracol.blogs.sapo.pt/hoje-e-primavera-em-paris-e-eu-nao-23080. Acesso em: 17 mar. 2019.

SEABRA, Joana. Criatividade. Artigo Online. Portal dos Psicólogos, 11 jul. 2008 https://www.psicologia.pt/artigos/textos/TL0104.pdf. Acesso em: 17 mar. 2019.

SIKORA, Joachim. Manual de métodos creativos. Buenos Aires: Kapelusz, 1979.

SODRÉ, Muniz. Antropológica do espelho. Uma teoria da comunicação linear e em rede. Petrópolis: Vozes, 2002.

STEVENSON, Robert. Comunicação pessoal. Sevilha, Espanha, 2015.

TORRANCE, Ellis. The nature of creativity as manifest in its testing In:

STERNBERG, Robert. (Ed.). The Nature of Creativity. New York: Cambridge University Press, 1988. p. 43-73.

WALLIN, Claudia. Finlândia faz 'maior reunião de pais e professores do mundo' para planejar educação do futuro. BBC, 7 nov. 2017. Disponível em: https:/ / www.bbc.com/portuguese/internacional-41865360. Acesso em: 7 mar. 2019. 